\title{
Editorial
}

\section{Viver sem limite, saúde e inclusão de pessoas com deficiência: novas perspectivas para a Enfermagem}

\author{
Wiliam César Alves Machado*
}

As novas configuraçóes que estão se delineando nos diversos contextos de prática social focadas na inclusão das pessoas com deficiência (PcD) na sociedade brasileira contemporânea apontam substantivas oportunidades para que a enfermagem amplie seu espectro de atuação, intervenção, reconhecimento social e identificação como fundamental para a promoçáo da saúde e qualidade de vida dessas pessoas. Para que tais oportunidades não sejam perdidas, entretanto, faz-se necessária profunda reavaliação do arcabouço de saberes e fazeres que norteiam as atividades de ensino, pesquisa, extensão e prática social da enfermagem, consoante com as novas exigências do mercado e pronta a atender as demandas que se apresentam.

É importante considerar que dados do Censo 2010 do Instituto Brasileiro de Geografia e Estatística (IBGE) [1] identificaram que 45,6 milhóes de pessoas possuem algum tipo de deficiência, no Brasil. Isso significa 23,91\% da população brasileira. O que sinaliza rico universo para imprescindíveis atividades da enfermagem, partindo de açôes e intervenções diagnósticas, intervencionistas e preventivas de saúde e reabilitação.

O Decreto no 7.612, de 17 de novembro de 2011, que institui o Plano Nacional dos Direitos da Pessoa com Deficiência - Viver sem Limite, e o teor da Portaria no 2.672, de 16 de novembro de 2011, trazem novas perspectivas para atuação da enfermagem, além da possibilidade para demarcação de novos campos de prática para suas futuras gerações $[2,3]$.

Nesse sentido, através de um conjunto de açôes estratégicas em educação, saúde, inclusão social e acessibilidade, o Plano Nacional para Pessoas com Deficiência tem o objetivo de promover a cidadania e o fortalecimento da participação da pessoa com deficiência na sociedade, promovendo sua autonomia, eliminando barreiras e permitindo o acesso e o usufruto, em bases iguais, aos bens e serviços disponíveis a toda a população.

Novas oportunidades para a enfermagem surgem também com a estruturação da Rede de Atenção à Saúde da Pessoa com Deficiência-SUS, que será um conjunto de serviços, açóes e estratégias de saúde com o objetivo de garantir a assistência integral a toda população que necessita deste tipo de atendimento, ao que nos impele maior preparo para superar lacunas no âmbito dos programas de formaçáo profissional em todos os níveis, adquirindo conhecimento para elaborar planejamento de assistência e cuidados de enfermagem específicos para atender as necessidades 
de pessoas com deficiência física, auditiva, visual, mental, múltipla e psicossocial.

Não nos será possível avançar na sintonia desses novos tempos sem que admitamos a necessidade de investir em grandes mudanças dos padróes atuais, no sentido de adequarmos nossa forma de interagir com pessoas desse segmento da sociedade. Interaçóes deficitárias têm caracterizado perfil dos serviços prestados por todos os profissionais da área de saúde, quando se trata dos serviços e atendimentos prestados às pessoas com deficiência, e com a enfermagem não é diferente.

Ainda agimos com passividade diante da falta de estrutura das nossas unidades de saúde, em todos os níveis de atendimentos, frequentemente, inacessíveis no ponto de vista arquitetônico, seja em suas áreas internas, seja em seus entornos. Admite-se sem maiores questionamentos éticos que sejam inauguradas, em nossos mais de 5.000 municípios, algumas milhares de unidades de saúde sem contemplar fundamentais preceitos de acessibilidade dispostos na NBR 9050/2004. Não nos parece incômodo, tampouco se constitui objeto de discussão da maioria a maldosa e perpetuada ausência de profissionais de enfermagem habilitados para a comunicação náo-verbal, nos diversos setores das nossas unidades de saúde, prontos para interagir adequadamente com surdos e lhes prestar cuidados e assistência digna.

Como se pode observar, muito temos a refletir, conhecer, aprender, reaprender e assumir que para conquistar esses novos territórios de prática profissional que se anunciam para a enfermagem, mudanças se fazem essenciais. A rede de reabilitação do SUS, por exemplo, é composta por diversos serviços especializados em deficiência física, visual, auditiva e intelectual, oficinas ortopédicas, unidades básicas de saúde e hospitais, voltados para o enfrentamento de problemas das pessoas com deficiência. Embora já implementada, ainda persistem lacunas na maioria dos programas de formação em enfermagem que sequer oferecem oportunidade para os estudantes aprenderem a cuidar dessas pessoas.

É importante acrescentar que os Centros Especializados de Reabilitaçáo (CER) serão implantados a partir de 2012. Mais ainda, que os CERs são serviços que agregam tecnologia para atender às várias modalidades de cuidado específicas para os diferentes tipos de deficiência, com qualidade e efetividade no cuidado. Não há tempo a perder!

Com efeito, a partir do programa "Viver Sem Limite", espera-se que o Brasil avance ainda mais na promoção da inclusão social das pessoas com deficiência, articulando e organizando açóes que foram aprimoradas e fortalecidas para eliminar barreiras e permitir o acesso desta população a bens e serviços.

\section{Referências}

1. Censo 2010 - Pessoas com Deficiência - Primeiros Resultados. [citado 2011 Dez 2]. Disponível em URL: http://saci.org.br/index.php? modulo=akemi \&parametro=33184

2. Brasil. Decreto $\mathrm{n}^{\mathrm{0}}$ 7.612, de 17 de dezembro de 2011. Institui o Plano Nacional dos Direitos da Pessoa com Deficiência - Viver sem Limite. Presidência da República. Casa Civil. Subchefia para Assuntos Jurídicos. Brasília (DF); 2011.

3. Brasil. Portaria no 2.672, de 16 de novembro de 2011. Institui o Comitê Nacional de Assessoramento e Apoio ás Açóes de Saúde do Plano Nacional de para Pessoas com Deficiência. Ministério da Saúde. Brasília (DF); 2011. 